\title{
Neurological Manifestations in Falciparum Malaria: A Study in Tribal Community of Hill Tracts
}

\author{
Islam $\mathrm{AT}^{1}$, Sultana $\mathrm{S}^{2}$, Rahman $\mathrm{M}^{3}$, Hoque $\mathrm{MA}^{4}$
}

\begin{abstract}
Objectives

The aim of this study is to find out the prevalence and outcome of falciparum malaria with neurological manifestations.
\end{abstract}

\section{Materials and Methods}

A prospective cross-sectional hospital-based study of 318 falciparum malaria patients using simple, direct, standardized questionnaire with history, lab investigations and neurological examination from January 2014 to December 2014

\begin{abstract}
Results
July was the most vulnerable month for falciparum malaria causing the highest hospital admission (48.8\%) and death $(29.3 \%)$. The commonest age group affected was $15-30$ years $(49.2 \%)$. Prevalence of neurological manifestations was $41.2 \%$. Altered sensorium $(48.7 \%)$ was the most frequent neurological manifestation, followed by abnormal behavior $(19.8 \%)$ and convulsions $(15.5 \%)$. Case fatality rate was very high with neurological manifestations, highest with altered sensorium (31.3\%). Perception of neurological manifestations among tribal was very poor. Primary health care providers also failed to diagnose most of the cases $(69 \%)$ which presented with neurological features.
\end{abstract}

\section{Conclusion}

Falciperum malaria with neurological involvement is associated with increased mortality. By documenting different neurological patterns of falciparum malaria and by trained health care personnel, mortality and morbidity rates can be reduced by early diagnosis and management.

CBMJ 2015 January: Vol. 04 No. 01 P: 18-21

Key words: Falciparum malaria, Neurological complications, Mortality.

\section{Introduction}

Malaria is not only common in malariaendemic areas; the disease is seen increasingly in Western countries as a result of people emigrating or traveling from such areas. The Plasmodium falciparum parasite is responsible for almost all the neurological complications associated with malaria. In 2002, an estimated 2.2 billion individuals were exposed to $P$. falciparum in malaria endemic areas, with 515 million clinical episodes and over 1 million deaths ${ }^{4}$. Over $70 \%$ of these infections occurred in children living in subSaharan Africa, although P. falciparum can infect humans at any age ${ }^{3}$. The neurological manifestations of malaria include seizures, psychosis, agitation, impaired consciousness and coma; the latter two features are the hallmarks of cerebral malaria. In malariaendemic areas, neurological features are found in nearly half of children admitted to

1. * Dr. Ahmed Tanjimul Islam

Medical Officer

Rangamati Sadar Hospital. Rangamati.

2. Dr. Shamrin Sultana

Medical Officer

Rangamati Sadar Hospital. Rangamati.

3. Dr. Matiur Rahman.

Associate professor \& head.

Department of Neurology

Sythet MAG Osmani Medical College Hospital.

4. Dr. Md. Azizul Hoque

Associate professor \& head

Department of Medicine.

Rajshahi Medical College Hospital.

Address of correspondence

Email :droveesomch@gmail.com Mobile: 01554333026 
hospital with falciparum malaria ${ }^{2,6}$. In areas where individuals develop severe disease, the proportions of patients who develop cerebral malaria are similar between children and adults. Cerebral malaria occurs in $2.4 \%$ of travelers with falciparum malaria, and has been well described ${ }^{2}$. Cerebral malaria is a rapidly evolving neurologic disease. It carries a fatality rate of more than $20 \%$ even in urban hospital settings where aggressive medical care is available ${ }^{10}$. However, the other neurological complications of falciparum malaria have received relatively little attention.

With neurological complications falciparum malaria causes more mortality and increases burden to society. In developing countries there are not enough qualified healthcare personnel to detect the neurological complications in early stage of disease. With history, investigations and examination the neurological complications can be detected in the early stage. The aim of this study is to find out the pattern of neurological manifestations of falciparum malaria to make early diagnosis of this fatal complication.

\section{Materials and Methods}

This is a descriptive prospective hospital based cross sectional study done for one year (January 2014 to December 2014) in Rangamati Sadar Hospital among tribal. All patients or their relatives gave their consent to participate in the study. A full detailed history and proper systemic and neurological examination was performed by the authors. The physical symptoms signs were grouped into general, systemic, and neurological. The diagnosis was confirmed with microscopic blood film examination (both thick and thin film) and rapid diagnostic test (RDT). Routine necessary lab tests were done to exclude other alternate diagnosis. Only Plasmodium falciparum cases were included in our study. Plasmodium vivax, ovale, malaria was very few in number and was excluded from the study. Impaired consciousness was diagnosed if patients had inappropriate or incomprehensible verbal responses and did not respond to verbal commands. Assessment of the patient was delayed for $6 \mathrm{hr}$ after a grand mal seizure to exclude postictal coma. History and examination were recorded on standard forms on admission. Patients were treated with a loading dose of $20 \mathrm{mg} / \mathrm{kg}$ quinine dihydrochloride infused intravenously over a $4 \mathrm{hr}$ period followed by $10 \mathrm{mg} / \mathrm{kg}$ over $4 \mathrm{hr}$ every eight hrs until oral quinine could be tolerated. Quinine was continued for seven to ten days. Neurological complications were searched thoroughly before and after treatment by central and peripheral nervous system examination. Data collected, tabulated and statistical analysis was performed using software SPSS-16.

\section{Results}

Total 318 patients of falciparum malaria admitted during the one year period with total death of 63 patients (19.8\%). Diagnosis was confirmed by blood film examination and RDT test. Highest admission rate was during the month of July ( $n=133,41.8 \%$ ) with highest death rate $(n=39,29.3 \%)$ in the same month. The incidence of the cases started to increase from the month of June $(n=54)$ with highest number of cases admitted in the month of July. (Figure-1)

Figure-1: Number of admission and death in falciparum malaria by month.

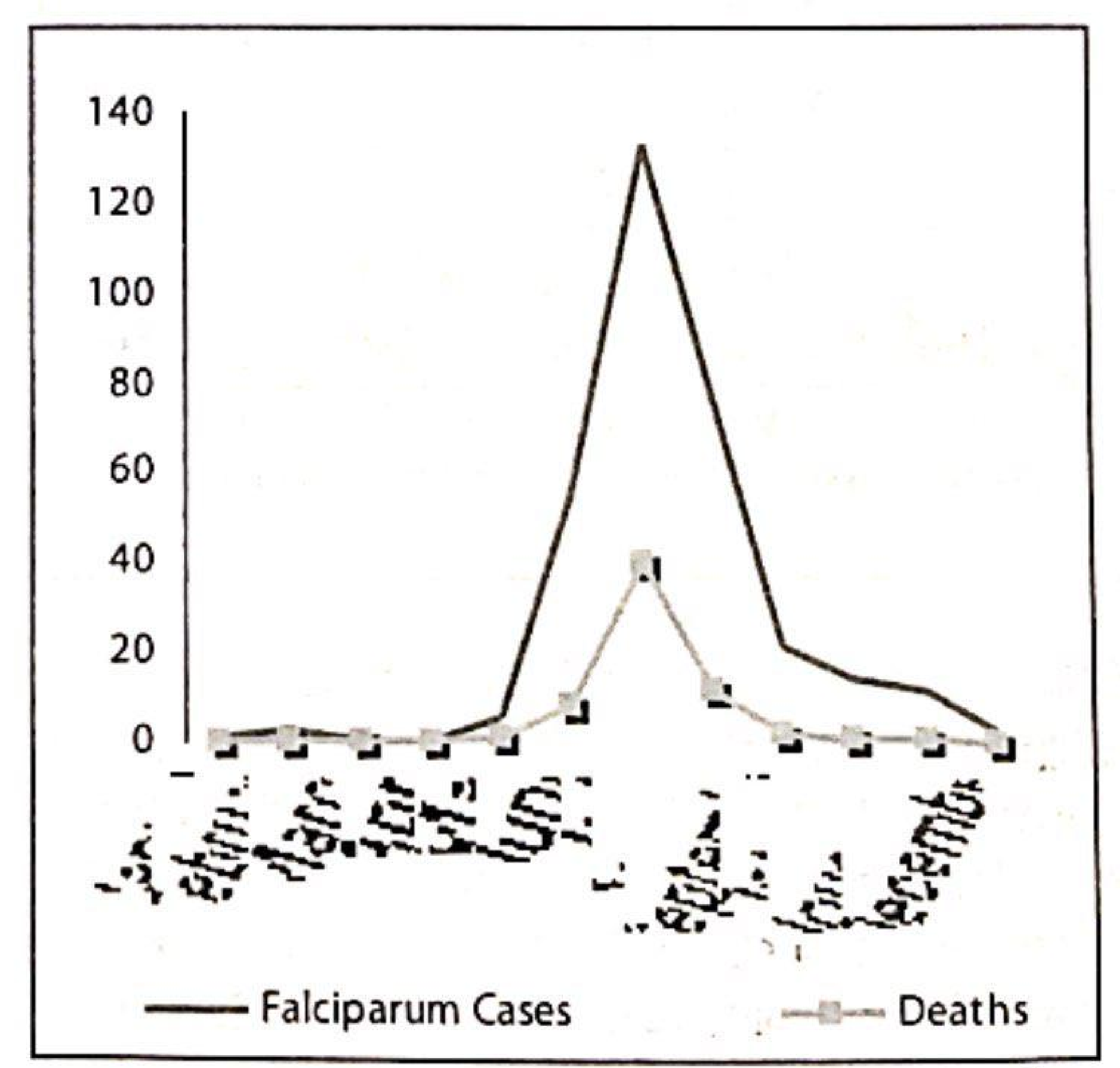


Our study revealed that of the total 318 case 187 cases presented with neurological manifestations on admission giving the prevalence of neurological manifestations in falciperum malaria 58.8\%. (Figure-2)

Figure-2: Number of cases of falciperum malaria with neurological manifestation.

- Without Neurological manifestations

Only with neurological manifeastations

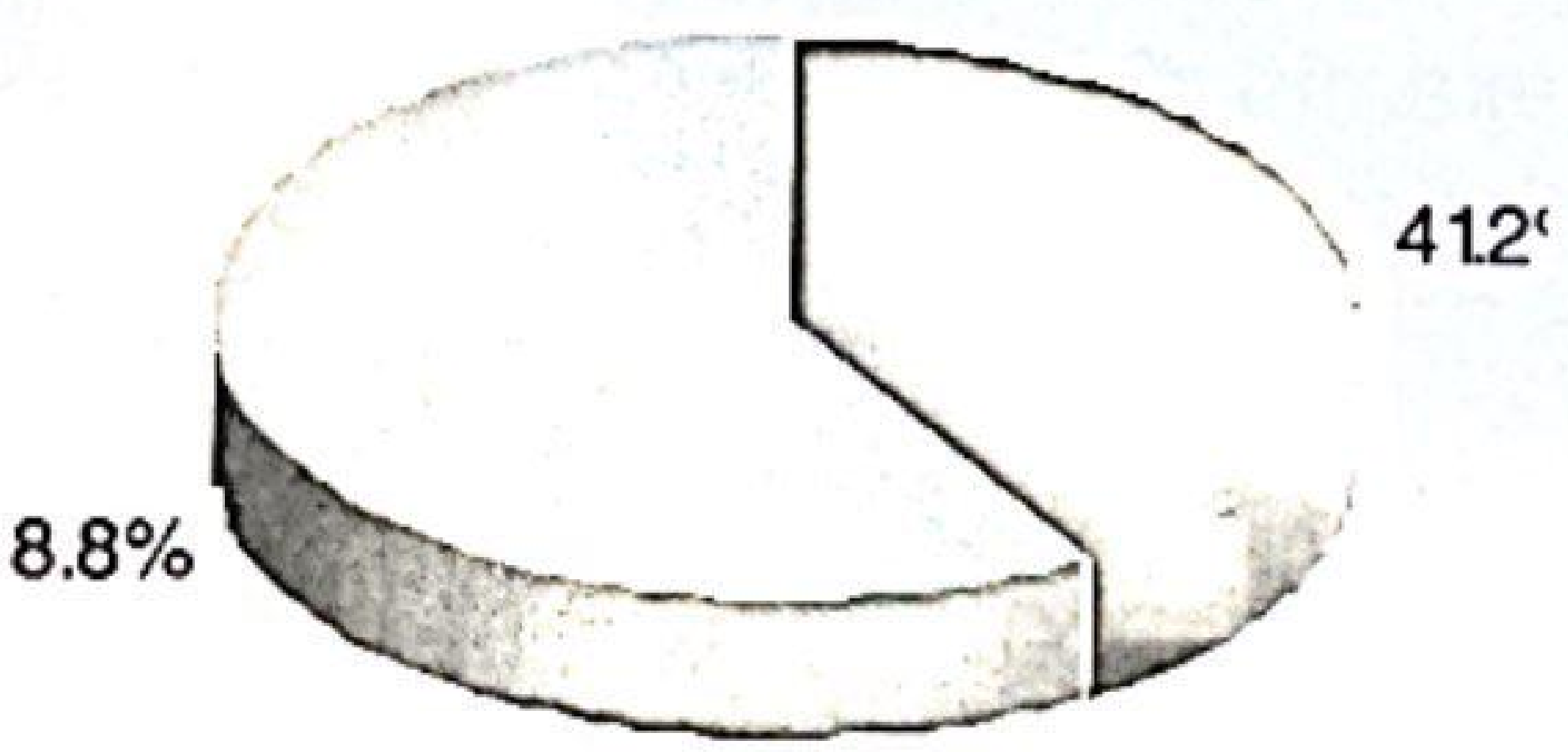

We also found the commonest age group admitted with neurological manifestation were $15-30$ years $(n=92,49.2 \%)$. Extreme age groups $<15$ years $(31 \%)$ and $>60$ years $(11 \%)$ had less neurological findings. (Figure-3)

Figure-3: Age group effected with neurological manifestations.

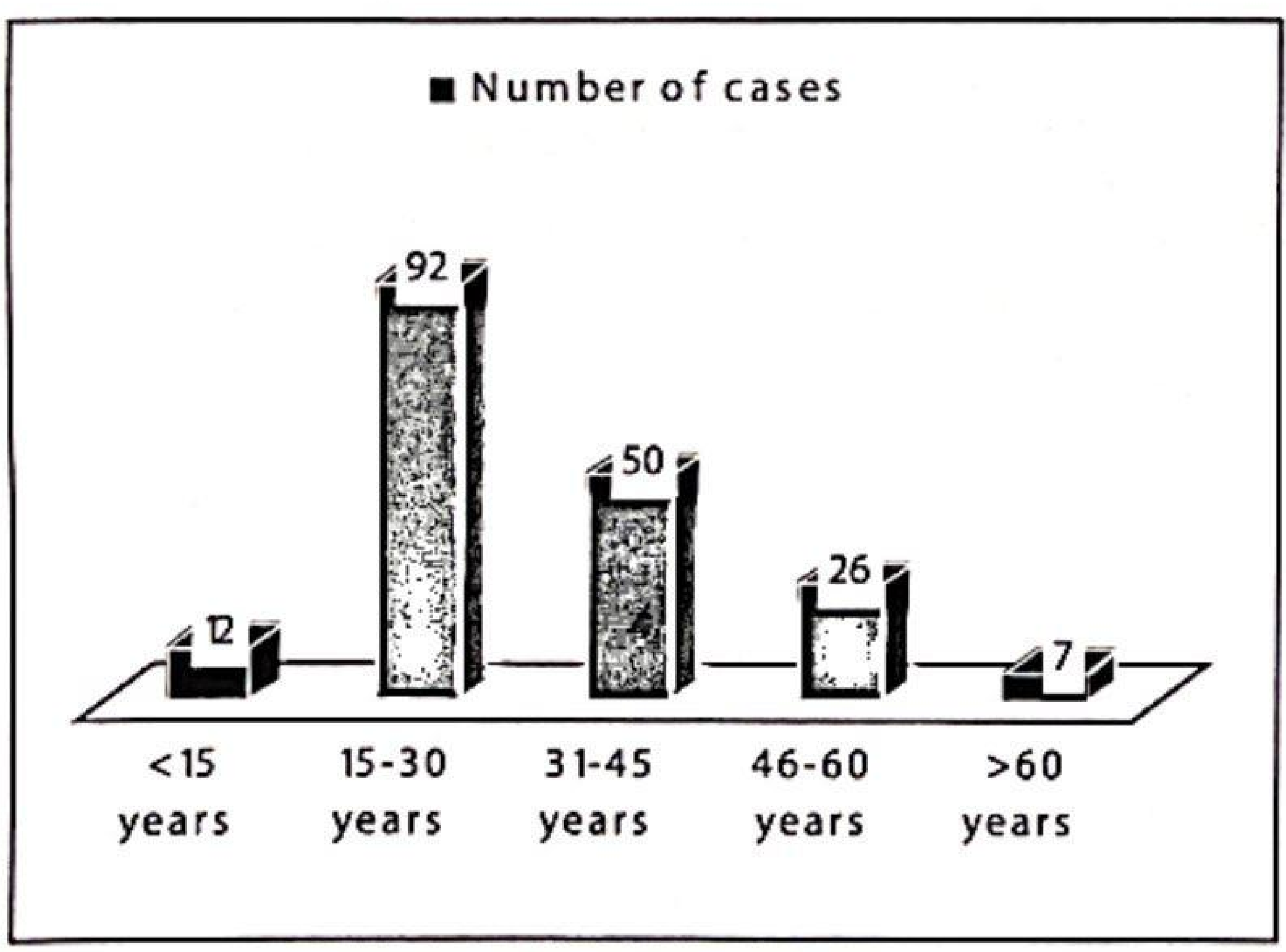

Six different forms of initial presentation on admission were found in 318 falciparum malaria patients. Neurological manifestations was the commonest form $(n=187,58.8 \%) .71$ cases presented with jaundice (22.3\%) which was alarming for changing trend. Other less common forms were severe anemia (11.3\%), renal impairment $(4.4 \%)$, shock $(2.5 \%)$ and ARDS (0.6\%). Number of death ( $n=49,26.2 \%)$ was very high in patients with neurological complications. In comparison, patients with non neurological manifestations had less mortality $(n=14,4.4 \%)$. (Figure-4)

Figure-4: Initial presentation at admission of falciparum malaria.

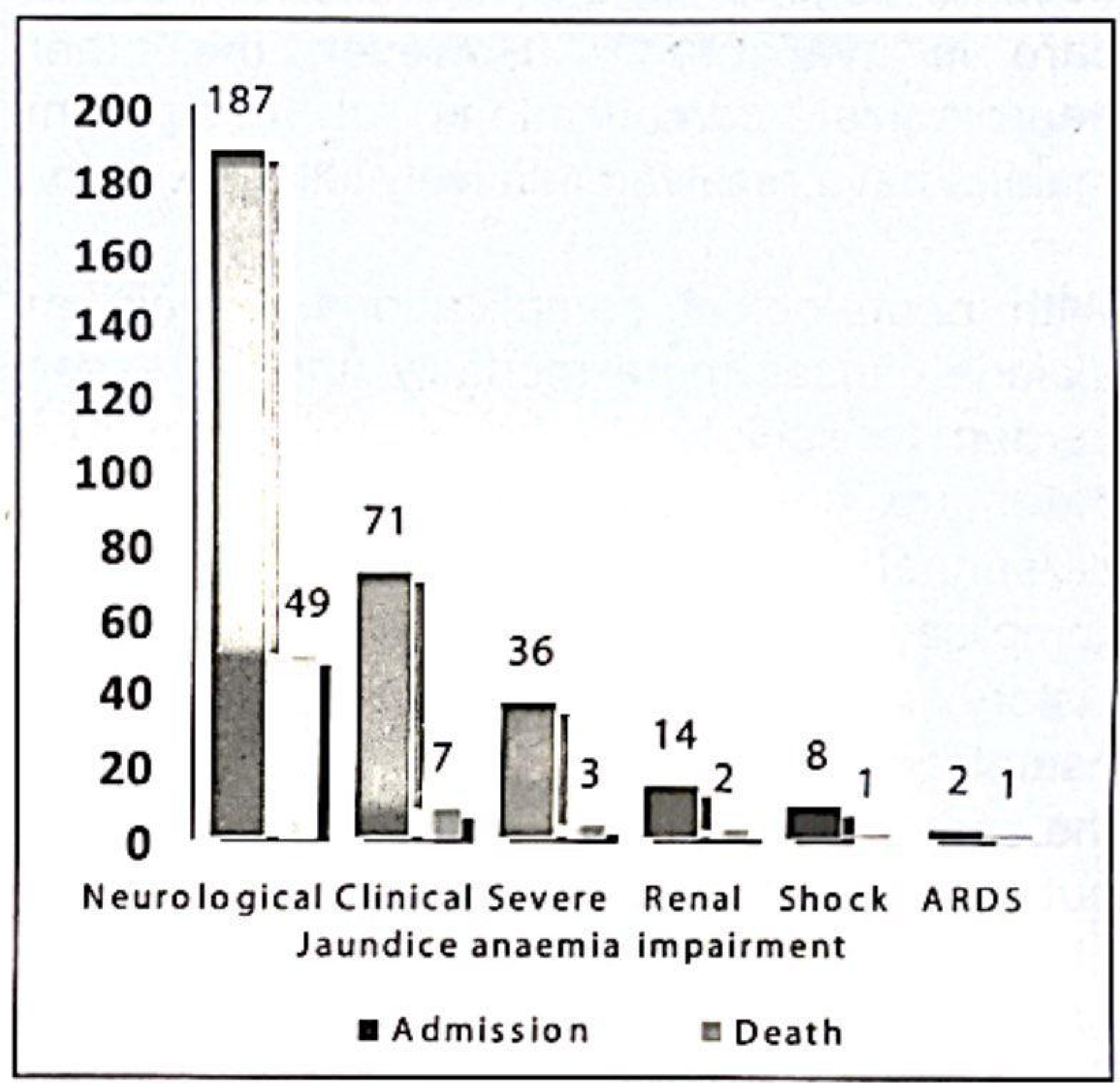

Of the total 187 patients with neurological manifestations which altered sensorium or coma ( $n=91,48.7 \%$ ) was the commonest form of neurological presentation. 37 (19.8\%) presented with altered behavior. 29 patients $(15.5 \%)$ had convulsion before or after admission. Others presented with delirium, headache, involuntary movements, dysarthria, hemiperesis and neck stiffness. Only 1 Patient presented with hiccough. (Figure-5)

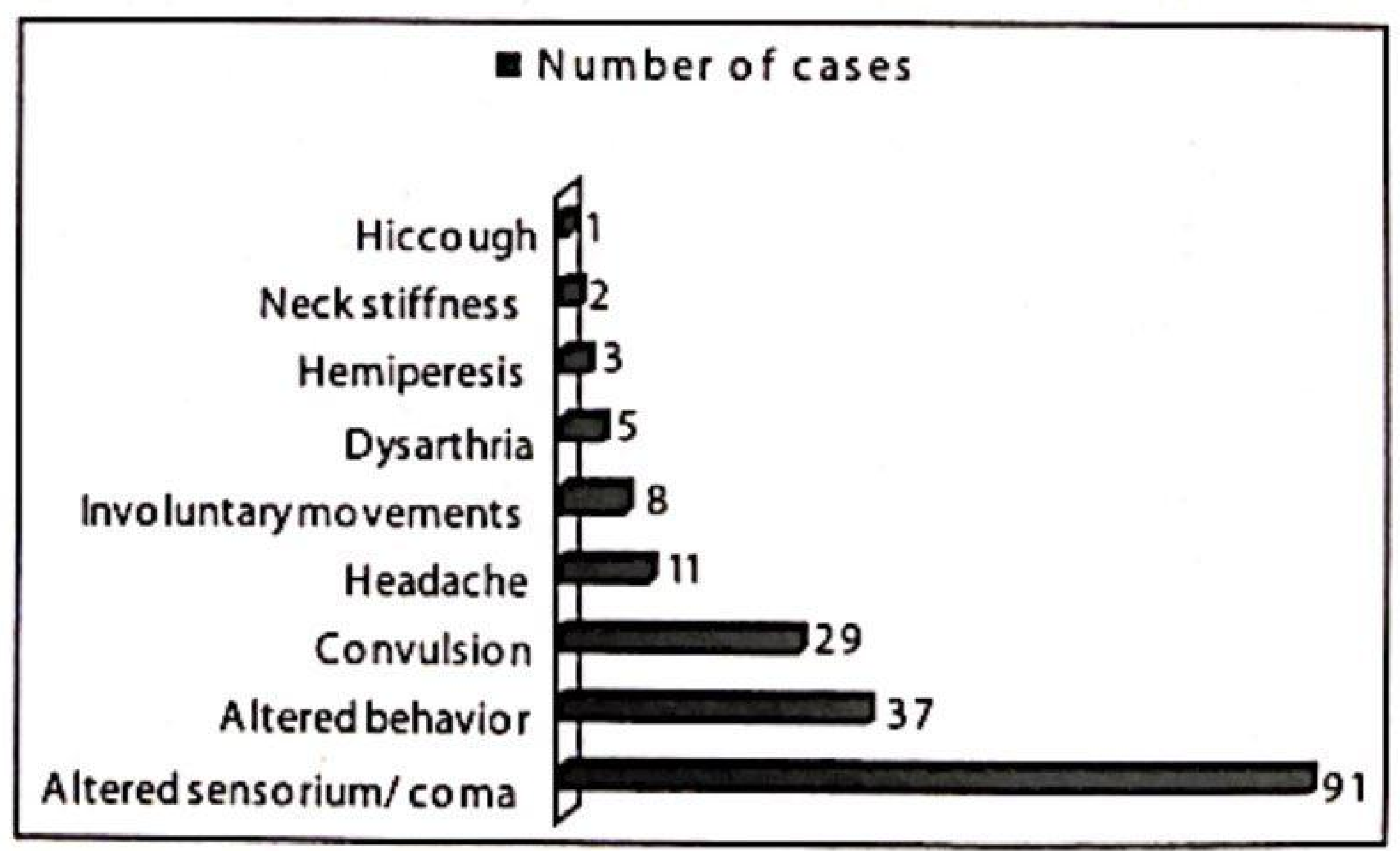

Figure-5: Neurological manifestations in falciparum malaria. 
infection rate was $0 \%$. Wu et $\mathrm{al}^{6}$ compared closed and open nailing in the segmental fractures and closed nailing showed better technique.

In Wiss et $\mathrm{al}^{7}$ study showed nonunion rate in closed nailing was half of open nailing and rate of nonunion was $1.8 \%$ and infection rate was $0 \%$ in close nailing. Christie et $\mathrm{al}^{8}$ showed mean union time was 17 weeks, with a range of 10 to 28 weeks and the rate of nonunion was $1.6 \%$ and infection rate was $0 \%$. Winquiest and Hansen ${ }^{9}$ study showed 520 patients of femoral shaft fracture $87 \%$ united within 3 months with the rate of nonunion was $9 \%$. Kempf et al ${ }^{10}$ study showed infection rate was $2.1 \%$ and the rate of nonunion was $7.6 \%$. In our study, rate of nonunion was $1.25 \%$, rate of infection was $3.75 \%$ and mean union time was 18 weeks. So, our study was compatible with the previous authors in respect of age groups, causes of fracture, time of union, rate of infection and rate of nonunion but dissimilar is only that majority of their cases were close nailing in respect of our open nailing. In our study excellent functional outcome found in $82.5 \%$, good in $12.5 \%$, fair in $5 \%$ of the patients and is compatible with previous study.

\section{Conclusion}

The study shows the antegrade interlocking intramedullary nailing is considered as gold standard in the treatment of the fracture shaft of the femur because the interlocking intramedullary nailing is revolutionary in the management of fracture shaft of femur, specially in fracture distal third, comminuted fracture \& in other unstable fracture. It decreases the chance of infection providing early mobilization of the patient thus facilitating early union of the fracture with good compliance.

\section{References}

1. Kuntscher G. Die marknagelong von knochenbruchen. Langenbecks Arch Chir. 1940;200:443-455.

2. Winquist RA. Hansen ST Jr. Clawson DK. Closed intramedullary nailing of femoral fractures. A report of five hundred and twenty cases. J Bone Joint Surg [Am]. 1984:66:529-39.

3. Klemm K. Borner M. Interlocking nailing of complex fracture of the femur and tibia.Clin. Orthop. 1986;212:89-100.

4. Apracioglu MO, Akmaz I, Mahirogullari M, Kiral A, Rodop O. Treatment of femoral shaft fractures by interlocking intramedullary nailing in adults. Acta Orthop Traumatol Turc. 2003;37:3.

5. Sojbjerg JO, Eiskjaer S, Moller-Larsen S. locked nailing of comminuted and unstable fractures of femur. J Bone Joint Surg. 1990 72B:23-25.

6. Wu CC, Shih GH, Yuang WN, Chen YJ. Treatment of segmental femoral shaft fracture. Clin Orthop. 1933; 287:224-230.

7. Wiss DA, Fleming GH, Mata JM, Clark D. Comminuted and rotationally unstable fractures of the femur treated with an interlocking nail. Clin Orthop. 1986;212:35-47.

8. Christie J, Court-Brown C. Femoral neck fracture during closed medullary nailing: Brief report. J Bone Joint Surg. 1988; 74B:6

9. Winquest RA, Hansen ST. Segmental fractures of the femur treated by closed intramedullary nailing. $J$ Bone Joint Surg. 1978; 69A: 934.

10. Kempf I, Grosse A, Beck J. Closed locked intramedullary nailing. Its application to comminuted fractures of the femur. J Bone Joint Surg. 1985; 67A: 709-720. 